\title{
Calciphylaxis in end-stage kidney disease: outcome data from the United Kingdom Calciphylaxis Study
}

\author{
Rajkumar Chinnadurai $^{1,2} \cdot$ Abby Huckle $^{2}$. Janet Hegarty ${ }^{1} \cdot$ Philip A Kalra $^{1,2} \cdot$ Smeeta Sinha $^{1,2}$ (i)
}

Received: 12 September 2020 / Accepted: 10 November 2020 / Published online: 6 February 2021

(c) The Author(s) 2021

\begin{abstract}
Background and aims Calciphylaxis is a rare condition associated with very high mortality in patients with end-stage kidney disease. Data from country-based registries have been an invaluable resource for a better understanding of the natural history and management for this condition. This study aimed to investigate the current management strategies and outcomes of patients enrolled in the United Kingdom Calciphylaxis study (UKCS).

Methods The study was conducted on 89 patients registered in the UKCS since 2012. The initial analysis included a description of the baseline characteristics, management strategies and outcomes on follow-up until May 2020. Further analysis included a comparison of the mortality outcome of the UKCS patients who were receiving haemodialysis with a propensity score matched cohort of haemodialysis patients from the Chronic Renal Insufficiency Standards Implementation StudyHaemodialysis (CRISIS-HD).

Results Median age of the cohort was 59 years, with a predominance of females (61\%) and Caucasian (95\%) ethnicity. About $54 \%$ of the patients were diabetic and $70 \%$ were receiving haemodialysis at study entry. The skin lesions were mostly distributed in the lower extremities (48\%). Sodium thiosulphate and calcimimetic were the most widely used management strategies. The mortality rate was 72 deaths per hundred patient-years (50 deaths observed in 69.5 patient years). Complete wound healing was noted in $17 \%$ and bacteraemia was reported in $26 \%$ of patients. In a comparative analysis of the matched haemodialysis patients, the presence of calciphylaxis in 62 patients showed a strong association with all-cause mortality (HR 6.96; $p<0.001$ ), with annual mortality $67 \%$ versus $10.2 \%$ in haemodialysis patients without calciphylaxis.

Conclusions This UK wide study strengthens the evidence that calciphylaxis is a strong and independent risk factor associated with all-cause mortality; no significant benefit was shown with any individual treatment modality. Until further evidence becomes available, a multifaceted approach would be the appropriate treatment strategy in the management of this extremely serious condition.
\end{abstract}

Smeeta Sinha

smeeta.sinha@srft.nhs.uk

1 Department of Renal Medicine, Salford Royal NHS

Foundation Trust, Salford M6 8HD, UK

2 Faculty of Biology, Medicine and Health, University of Manchester, Manchester, UK 


\section{Graphic abstract}

\section{Calciphylaxis in end-stage kidney disease: outcome data from the United Kingdom}

Calciphylaxis Study

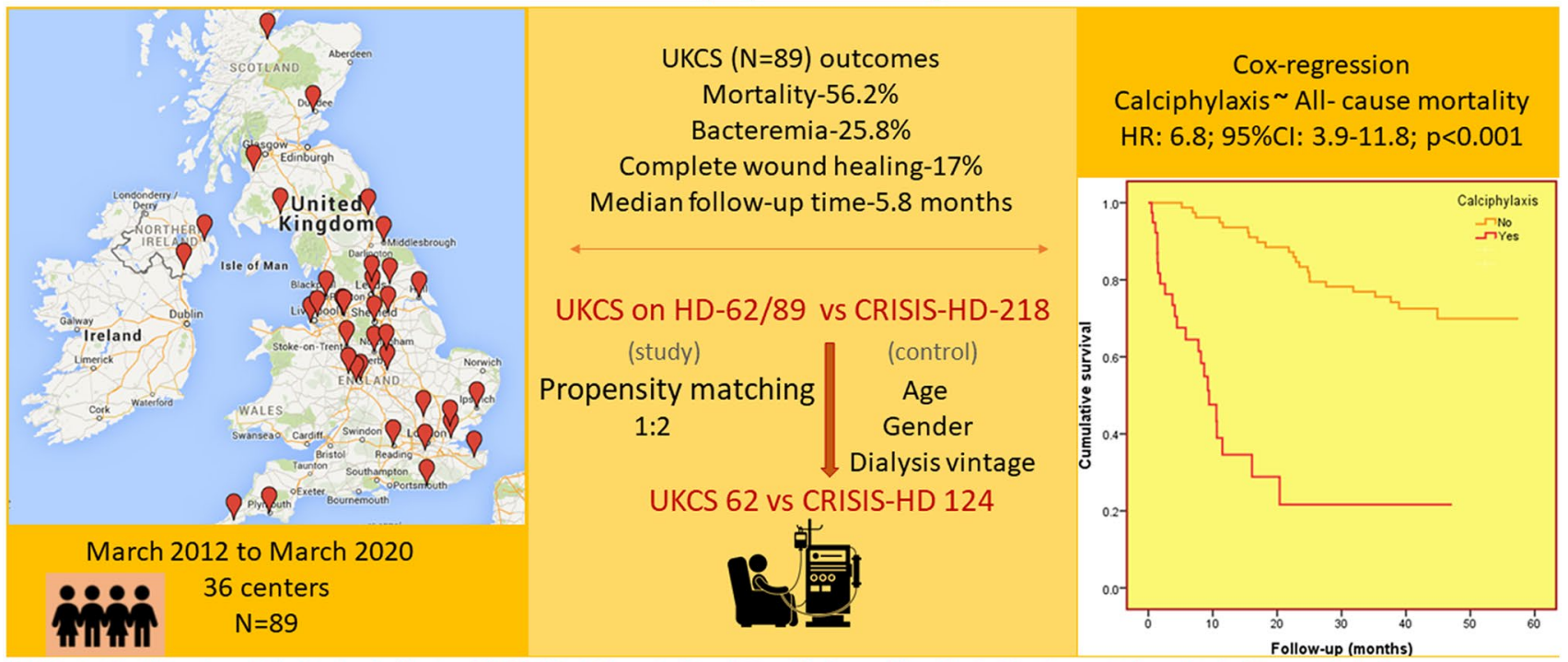

UKCS- United Kingdom Calciphylaxis Study; CRISIS-HD- Chronic Renal Insufficiency Standards Implementation Study-Haemodialysis

Keywords Calciphylaxis $\cdot$ End-stage kidney disease $\cdot$ Haemodialysis $\cdot$ Mortality

\section{Introduction}

Calciphylaxis, or calcific uremic arteriolopathy (CUA), is a rare but deleterious condition in which small arterioles within the skin become calcified. This in turn results in classically painful skin lesions, particularly in patients with endstage kidney disease (ESKD). The reported prevalence of CUA in dialysis patients ranges from $1-4 \%$, with an annual incidence of around $0.04 \%[1,2]$. The annual mortality rate is reported to be as high as $60 \%$ in patients with CUA [3]. Despite the high mortality rate, there are no diagnostic tests or licensed treatments for the condition. Researchers have, however, identified potential risk factors that may be associated with worse outcomes in CUA. Risk factors including cardiovascular disease, diabetes mellitus and warfarin use have been associated with all-cause mortality in patients with CUA possibly due to co-existing systemic vascular calcification [4]. The management of CUA remains problematic as clinicians have largely relied on case series and small uncontrolled studies for guidance. Several agents such as sodium thiosulphate, calcimimetics [5], bisphosphonates [6] and vitamin $\mathrm{K}$ have been identified as showing promise in small studies, although real benefit of these agents in isolation is still under debate [7-9]. Country-based registries and studies have been a major resource in providing data on the natural history and outcomes of CUA [10].
Ongoing evaluation of real-world management strategies and outcomes are warranted for optimising care in this poorly understood condition.

This study aims to investigate the management strategies and outcomes of patients with CUA registered in the United Kingdom (UK) calciphylaxis study. Adding to this, the study also compares the outcomes and the strength of association of calciphylaxis in haemodialysis patients with a matched group of patients who received haemodialysis but without development of calciphylaxis.

\section{Methods}

The United Kingdom Calciphylaxis Study (UKCS) is an ongoing nationwide prospective observational cohort study. The first patient was recruited to the study in 2012; details of patient recruitment is described online at www.calciphyla xis.org.uk. Currently around 36 renal centres across the UK have recruited patients to the study. In brief, any chronic kidney disease patient, including patients with ESKD receiving dialysis, diagnosed with calciphylaxis from any UK renal department is approached to be consented and recruited to this study at the time of diagnosis. At study baseline (consent date), details including demographics, concomitant medications, standard laboratory variables and clinical 
information on skin lesions, symptoms, and initial therapeutic interventions is collected. In addition, blood samples for DNA analysis, plasma/serum for biomarkers and clotting samples are collected and stored at $-80{ }^{\circ} \mathrm{C}$ for future analysis. Follow-up clinical and laboratory data is collected every four months for all patients until the study endpoints of complete wound healing or death. The study gained ethical approval from the National Research Ethics Service (reference: $11 / \mathrm{NW} / 0528)$.

An initial cross-sectional analysis was carried out on 89 patients with complete follow-up datasets in the UKCS between June 2013 and May 2020. The analysis included a description of baseline characteristics, management strategies and outcomes. Of the 89 patients, 62 were receiving haemodialysis at UKCS entry. These 62 patients were separately considered with a propensity matched group from the Chronic Renal Insufficiency Standards Implementation Study-Haemodialysis (CRISIS-HD) database for a comparative analysis (Fig. 1).

The CRISIS-HD was a prospective study which recruited haemodialysis patients between March 2012 and 2014, and is now subsumed into the Salford Kidney Study. Patient recruitment into CRISIS-HD is described in published literature $[11,12]$. In summary, patients aged $>18$ years old receiving maintenance haemodialysis at Salford Royal hospital and its four satellite units (a tertiary renal centre in the United Kingdom with a catchment population of 1.55 million) were approached to be consented for participation in this study. The exclusion criteria were the inability to participate due to illness or poor mobility and incapacity to consent; a total of 218 patients were recruited into CRISIS-HD.

At CRISIS-HD study baseline (consent date), data including demographics, comorbidities, laboratory results and three month-averaged dialysis details were recorded from electronic patient records (EPR). All CRISIS-HD patients were followed up until the study endpoints which included

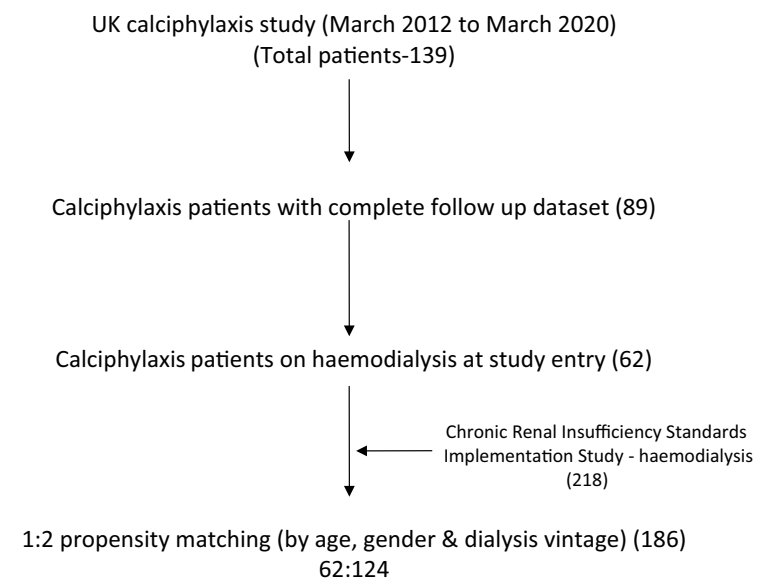

Fig. 1 Flowchart of patient sampling renal transplantation, death, and the study end date of 31 December 2016. Transplantation and mortality records were gathered from EPR. The CRISIS-HD adhered to the Declaration of Helsinki and has ethical approval for all observational data (REC 05/Q1404/188).

The 62 UKCS patients were matched for age, gender and dialysis vintage (years receiving dialysis) with the 218 patients in the CRISIS-HD cohort by propensity score matching. Matching was undertaken by $1: 2$ neighbour matching of patients with the same propensity scores as generated by the R software (version 3.5.1) 'MatchIt' package $[13,14]$ (Supplementary Fig. 1). The resultant matched cohort of 186 patients were used for comparative analysis. In the descriptive analysis of the comparative data, the MannWhitney U test was used to generate p-values for continuous data and the Chi-square test was used for obtaining p-values for categorical data. Univariable and multivariable Cox-regression analysis was used to study the strength of the association between the presence of calciphylaxis and all-cause mortality. Multivariable models were developed by adjusting for factors that were statistically significant in the univariable model. Due to the small number of events, a maximum of six variables were included in each of the multivariable models to preserve stability [15]. The proportional hazard assumption was examined and met by plotting the log-minus-log survival curves and survival times against cumulative survival. Kaplan-Meier survival curves were used to illustrate cumulative survival between the groups. All analysis was performed using SPSS (version 22), licenced to the University of Manchester.

\section{Results}

\section{United Kingdom Calciphylaxis Study (UKCS) outcomes}

The median age of the 89 patients in the UKCS cohort was 59 years with a predominance of females (61\%) and Caucasians (95\%). At study entry a majority $(70 \%)$ were receiving haemodialysis, $18 \%$ were receiving peritoneal dialysis, and $12 \%$ were non-dialysis chronic kidney disease patients. The diagnosis of calciphylaxis was made by clinical impression in $52(58.5 \%)$ patients, by clinical impression and radiology of soft tissue in $5(5.5 \%)$ patients, and by skin biopsy in $33(37 \%)$ patients. Fifty-four per cent were diabetic, with a median body mass index of the cohort being $31 \mathrm{~kg} / \mathrm{m}^{2}$. Vitamin D analogues were prescribed for $68 \%$, with $41 \%$ receiving a vitamin $\mathrm{K}$ antagonist. The skin lesions were predominantly distributed in the lower extremities (49\%) followed by the abdomen (30\%) and thighs (25\%). The median haemoglobin and albumin values were reduced compared to the normal range values; however, the c-reactive protein was 
elevated (Table 1). A comparison of baseline characteristics between the patients who had complete wound healing and those who did not showed a statistically significant higher haemoglobin and serum albumin and a lower c-reactive protein in the healed group (supplementary Table 1).

Table 1 Baseline characteristics of the UKCS patients

\begin{tabular}{|c|c|}
\hline Variable & Total-89 \\
\hline Age, years & $59(53-69)$ \\
\hline Gender, female & $54(60.6 \%)$ \\
\hline Ethnicity, Caucasian & $84(94.4 \%)$ \\
\hline Body mass index, $\left(\mathrm{Kg} / \mathrm{m}^{2}\right)$ & $31(25-38)$ \\
\hline \multicolumn{2}{|l|}{ Renal status at diagnosis } \\
\hline Non-dialysis chronic kidney disease & $11(12.4 \%)$ \\
\hline Haemodialysis & $62(69.6 \%)$ \\
\hline Peritoneal dialysis & $16(18.0 \%)$ \\
\hline \multicolumn{2}{|l|}{ Co-morbidities } \\
\hline Ischaemic heart disease & $35(39.3 \%)$ \\
\hline Myocardial infarction & $20(22.5 \%)$ \\
\hline Cerebrovascular disease & $12(13.5 \%)$ \\
\hline Peripheral vascular disease & $14(15.7 \%)$ \\
\hline Diabetes mellitus & $48(53.9 \%)$ \\
\hline Bone fractures & $2(2.25 \%)$ \\
\hline Hypertension & $58(65.2 \%)$ \\
\hline Parathyroidectomy & $8(8.9 \%)$ \\
\hline \multicolumn{2}{|l|}{ Medications } \\
\hline Vitamin D analogues & $40(44.9 \%)$ \\
\hline Calcium based phosphate binders & $14(15.7 \%)$ \\
\hline Calcimimetics & $17(19.1 \%)$ \\
\hline Vitamin K antagonist (warfarin) & $24(26.9 \%)$ \\
\hline \multicolumn{2}{|l|}{ Distribution of skin lesions } \\
\hline Abdomen & $24(26.9 \%)$ \\
\hline Breast & $6(6.7 \%)$ \\
\hline Lower extremities (leg/calf/toes) & $43(48.3 \%)$ \\
\hline Thighs & $22(24.7 \%)$ \\
\hline Buttock & $8(9 \%)$ \\
\hline Groins/genitalia & $4(4.5 \%)$ \\
\hline Hands and fingers & $6(6.7 \%)$ \\
\hline \multicolumn{2}{|l|}{ Laboratory results } \\
\hline Haemoglobin, g/L & $94(82-111)$ \\
\hline Albumin, g/L & $27(22-35)$ \\
\hline Corrected calcium, mmol/L & $2.39(2.24-2.53)$ \\
\hline Phosphate, mmol/L & $1.66(1.13-2.01)$ \\
\hline Alkaline phosphatase, units/L & $157(104-269)$ \\
\hline Parathyroid hormone ${ }^{\mathrm{a}}, \mathrm{ng} / \mathrm{L}$ & 329.5 (78-679) \\
\hline C-reactive protein ${ }^{\mathrm{b}}, \mathrm{mg} / \mathrm{L}$ & $65(14-145)$ \\
\hline
\end{tabular}

Categorical variables expressed as number (percentage) and continuous variables expressed as median (interquartile range)

UKCS United Kingdom calciphylaxis study

${ }^{\text {a }}$ Missing Parathyroid hormone levels in 32 patients

${ }^{\mathrm{b}}$ Missing CRP in 7 patients
The median duration of follow-up was 5.8 months; $17 \%$ of patients had complete wound healing, and $56.2 \%$ of the cohort died during the study period (June 2013 and May 2020). The mortality rate was 72 deaths per hundred patient-years (50 deaths observed in 69.5 patient-years). The mortality rate of the non-dialysis CKD patients with calciphylaxis (11 patients at recruitment) was 82 deaths per hundred patient-years ( 8 deaths observed in 9.75 patientyears), although four patients were commenced on dialysis after study entry. The median time for wound healing after study entry was eight months, with the median survival time being four months (Table 2).

The various strategies used in the management of calciphylaxis are listed in Table 3. More than $65 \%$ of patients received sodium thiosulphate, followed by calcimimetic use in $41 \%$ specifically as a medical intervention for the treatment of calciphylaxis. Other approaches included increased

Table 2 Outcomes from the UKCS patients

\begin{tabular}{ll}
\hline Outcome & Results in 89 patients \\
\hline Follow-up, months & $5.8(2-11.6)$ \\
Bacteraemia & $23(25.8 \%)$ \\
Complete wound healing & $15(16.8 \%)$ \\
Time for wound healing, months & $8(3-23)$ \\
Total death & $50(56.2 \%)$ \\
Survival time, months & $4(1-9)$ \\
\hline
\end{tabular}

Categorical variables expressed as number (percentage) and continuous variables expressed as median (interquartile range)

UKCS United Kingdom calciphylaxis study

Table 3 Management strategies used specifically for treatment of calciphylaxis

\begin{tabular}{lr}
\hline Management strategies & \multicolumn{1}{l}{$\begin{array}{l}\text { Total-89 } \\
\text { number }(\%)\end{array}$} \\
\hline Calcimimetics (cinacalcet) & $36(40.5 \%)$ \\
Sodium thiosulphate & $59(66.3 \%)$ \\
Increased dialysis frequency & $17(19.1 \%)$ \\
Dialysis calcium concentration reduced & $20(22.5 \%)$ \\
Wound debridement & $18(20.2 \%)$ \\
Stopping calcium binders & $20(22.5 \%)$ \\
Stopping/reducing vitamin-D analogues & $23(25.8 \%)$ \\
Stopping warfarin & $12(13.4 \%)$ \\
Bisphosphonates & $4(4.5 \%)$ \\
Antibiotics (intravenous) & $27(30.3 \%)$ \\
Antibiotics (oral) & $14(15.7 \%)$ \\
Hyperbaric oxygen & $4(4.5 \%)$ \\
Skin graft & $3(3.5 \%)$ \\
Amputation & $3(3.5 \%)$ \\
\hline
\end{tabular}

UKCS United Kingdom calciphylaxis study, p-value by chi-square test 
dialysis frequency, surgical wound care and cessation of calcium binders, warfarin and vitamin-D analogues. The treatment approaches were not protocolled by the study and there was variation in practice across the centres. In addition to systemic treatments, local wound treatments described included wound debridement $(20 \%)$ and skin grafting $(3.5 \%)$.

\section{UKCS and Salford Kidney Study-Haemodialysis (CRISIS-HD) matched analysis}

The groups were well matched for age, gender and dialysis vintage after propensity score matching. A higher prevalence of diabetes was observed in the UKCS group ( $48 \%$ vs. $37 \%, p=0.14$ ), although the difference was not statistically significant. Patients in the UKCS group had a higher median body mass index ( $32 \mathrm{vs.} 27 \mathrm{~kg} / \mathrm{m}^{2}$, p-value $=0.001$ ) and they had a higher prevalence of cardiovascular disease: history of ischemic heart disease, myocardial infarctions and peripheral vascular disease. A significantly higher proportion of deaths were noted in the UKCS group (53\% vs. $31 \%$, p-value $=0.004$ ) resulting in a shorter median follow up period (7 vs. 39 months, p-value $<0.001)$. The age at death was much lower in the UKCS cohort (59 vs. 72 years, $p=0.001$ ). The UKCS cohort had much higher mortality rate; 67 deaths per hundred patient-years (33 deaths observed in 49.6 patient-years), compared to the CRISISHD cohort; 10.2 deaths per hundred patient-years (39 deaths observed in 382.6 patient-years). The UKCS patients had a significantly lower haemoglobin, albumin and a higher c-reactive protein. The median parathyroid hormone level was higher in the UKCS cohort, although this was statistically different ( 326 vs. $200 \mathrm{ng} / \mathrm{L}, \mathrm{p}=0.29$ ). There was a statistically significant difference between some prescribed medications at study entry, with a higher proportion on erythropoietin stimulating agents and vitamin $\mathrm{K}$ antagonists in the UKCS cohort ( $p<0.001$ for both the drugs) (Table 4$)$.

In a univariable cox-regression model, the presence of CUA showed a very strong association with all-cause mortality (HR: 6.96; 95\% CI 4.1-11.7; p < 0.001) (Table 5). A history of myocardial infarction was also found to be significantly associated with all-cause mortality in this model (HR: 2.76; 95\% CI 1.54-4.98; $p=0.001$ ). The strength of association of CUA extended to the multivariable model for mortality which included factors that were significant in the univariable model (HR: 6.8; 95\% CI 3.9-11.8; $\mathrm{p}<0.001$ ) (Table 6). Other factors including older age, Caucasian ethnicity, diabetes, lower haemoglobin and albumin were noted to be strongly associated with all-cause mortality. The Kaplan-Meier plot demonstrates a significantly worse survival in patients with CUA (log-rank, p-value $<0.001$ ) (Fig. 2).

\section{Discussion}

Our data provides an overview of the natural history, current management strategies and outcomes of end- stage renal disease patients with calciphylaxis in the UK. The UKCS had a predominance of female and Caucasian distribution which is in agreement with previous observations, although the aetiology behind this association is still unexplained [16]. A high prevalence of diabetes and the higher median BMI noted in the UKCS patients were similar to that reported by Nigwekar et al. [17]. Both these findings support the possible link between calciphylaxis and the metabolic syndrome [18]. In addition, obesity and the distribution of skin lesions predominantly in adipose tissue rich areas (abdomen and thighs) noted in our cohort, is concordant with the mechanisms postulated for the development of CUA including increased arteriolar tensile stress and reduced local blood flow [19]. The diagnosis of calciphylaxis can be challenging and a vigilant clinical acumen is warranted to make a prompt diagnosis. The role of skin biopsy in the diagnosis of CUA is debatable [20]. A significantly higher c-reactive protein and a lower albumin and haemoglobin observed at calciphylaxis diagnosis in the UKCS is likely a reflection of the inflammatory nature of the condition. Inflammation is likely to be caused by calciphylaxis but may also contribute to the development of it; inflammatory mediators have been shown to induce vascular calcification in animal models and systemic calcification is also seen in inflammatory conditions [21-23]. Although extremely high, the mortality rate (72 deaths per hundred patient-years) and the median survival time (4 months) in the overall cohort is actually improved compared to that reported by Weenig et al. [3], probably attributed to a better understanding of the condition over the years and the multifaceted approach in the management. The devastating mortality of the condition is also highlighted in the propensity matched analysis of the 62 affected haemodialysis patients with annual mortality $67 \%$ versus only $10.2 \%$ in unaffected haemodialysis patients. Our study shows that the CUA wounds are slow to heal (median healing time (MHT)- 8 months), in keeping with the French (MHT- 6.4 months) and Australian registries (MHT- 8 months) [10, 24]. Patients in the UKCS group were more likely to be receiving calcimimetics and vitamin $\mathrm{K}$ antagonist, similar to other registry studies [17]. Warfarin inhibits the vitamin $\mathrm{K}$-dependent carboxylation of the vascular calcification inhibitor, matrix-Gla protein thereby also providing biological plausibility to the hypothesis that vitamin $\mathrm{K}$ antagonists increase the risk of CUA [25]. These data have unsurprisingly generated significant interest in the 
Table 4 Comparison of baseline characteristics and follow-up events between UKCS and CRISIS-HD cohort in a matched sample

\begin{tabular}{|c|c|c|c|}
\hline \multirow[b]{2}{*}{ Variables } & \multicolumn{3}{|c|}{ Matched sample (186) } \\
\hline & $\begin{array}{l}\text { UKCS } \\
(62)\end{array}$ & $\begin{array}{l}\text { CRISIS-HD } \\
\text { (124) }\end{array}$ & p-value \\
\hline \multicolumn{4}{|l|}{ Baseline } \\
\hline Age, years & $59(53-70)$ & $63(51-72)$ & 0.39 \\
\hline Gender, female & $39(63 \%)$ & $69(56.5 \%)$ & 0.34 \\
\hline Ethnicity, Caucasian & $59(95.1 \%)$ & $101(81.5 \%)$ & 0.01 \\
\hline Body mass index ${ }^{\mathrm{a}}, \mathrm{Kg} / \mathrm{m}^{2}$ & $32(25-38)$ & $27(23.1-30.6)$ & 0.001 \\
\hline Diabetes mellitus & $30(48.4 \%)$ & $46(37.1 \%)$ & 0.14 \\
\hline Ischemic heart disease & $25(40.3 \%)$ & $21(16.9 \%)$ & $<0.001$ \\
\hline Myocardial infarctions & $14(22.5 \%)$ & $9(7.3 \%)$ & $\mathbf{0 . 0 0 3}$ \\
\hline Peripheral vascular disease & $11(17.7 \%)$ & $9(7.3 \%)$ & 0.03 \\
\hline Cerebrovascular accident & $9(14.5 \%)$ & $8(6.5 \%)$ & 0.07 \\
\hline Dialysis vintage, months & $54(17-100)$ & $38(11-81)$ & 0.17 \\
\hline Corrected calcium, mmol/L & $2.32(2.2-2.5)$ & $2.34(2.3-2.45)$ & 0.43 \\
\hline Phosphate, $\mathrm{mmol} / \mathrm{L}$ & $1.64(1.12-1.85)$ & $1.51(1.08-1.80)$ & 0.34 \\
\hline Parathyroid hormone $^{\mathrm{b}}, \mathrm{ng} / \mathrm{L}$ & $326(76-695)$ & $200(114-441)$ & 0.29 \\
\hline Albumin, $g / L$ & $29(23-35)$ & $39(35-41)$ & $<0.001$ \\
\hline Haemoglobin, g/L & $94(82-107)$ & $107(99-116)$ & $<0.001$ \\
\hline C-reactive protein ${ }^{\mathrm{c}}, \mathrm{mg} / \mathrm{L}$ & $41(10-116)$ & $8.2(3.3-20)$ & $<0.001$ \\
\hline Erythropoietin stimulating agents & $39(62.9 \%)$ & $29(23.4 \%)$ & $<0.001$ \\
\hline Vitamin D analogue & $37(59.7 \%)$ & $62(50 \%)$ & 0.212 \\
\hline Calcium containing phosphate binder & $10(16.1 \%)$ & $30(24.2 \%)$ & 0.21 \\
\hline Calcimimetic (cinacalcet) & $12(19.3 \%)$ & $13(10.5 \%)$ & 0.09 \\
\hline Vitamin K antagonist (warfarin) & $22(35.5 \%)$ & $9(7.3 \%)$ & $<0.001$ \\
\hline \multicolumn{4}{|l|}{ Follow-up } \\
\hline Follow-up, months & $6.8(2.0-11.5)$ & $39(32-45)$ & $<0.001$ \\
\hline Total deaths & $33(53.2 \%)$ & $39(31.5 \%)$ & 0.004 \\
\hline Age at death, years & $59(53-69)$ & $72(65-79)$ & $<0.001$ \\
\hline
\end{tabular}

Continuous data median (inter quartile range) with p-value by Mann-Whitney U test. Categorical data expressed as number (percentage) with Chi-square test for $\mathrm{p}$-value

UKCS United Kingdom calciphylaxis study, CRISIS-HD Chronic Renal Insufficiency Standards Implementation Study-Haemodialysis

${ }^{a}$ Missing body mass index values for 11 patients in the UKCS group

${ }^{\mathrm{b}}$ Missing parathyroid hormone levels in 23/62 of UKCS group and 41/124 of CRISIS-HD group

${ }^{\mathrm{c}}$ Missing c-reactive protein for 3 patients in the calciphylaxis study group use of vitamin $\mathrm{K}$ as a treatment for calciphylaxis. The use of vitamin $\mathrm{K}$ in our cohort was limited, therefore we are unable to draw any meaningful conclusions, however, we await the publication of Nigwekar et al's randomised controlled trial which investigates the impact of phytomenadione on wound healing and all-cause mortality in 26 patients with CUA (NCT02278692).

Uncontrolled secondary hyperparathyroidism (SHPT) has been associated with an increased risk of calciphylaxis. The increased use of cinacalcet at baseline (19\%) in the UKCS cohort may therefore represent underlying SHPT rather than a causative association. Deen et al. have suggested the beneficial effects of cinacalcet as a treatment for CUA in a recent review [26]. The EVOLVE study also suggested that patients receiving cinacalcet for SHPT were less likely to develop calciphylaxis; 18 patients assigned to placebo developed calciphylaxis versus six assigned to cinacalcet [27].

Sodium thiosulphate (STS) is widely used in the management of CUA, but a significant benefit with its use was not observed in our cohort. In a recent systematic review of 45 studies, sodium thiosulphate was identified as a potentially promising treatment in the management of CUA, however, its efficacy in modifying outcomes such as wound healing and pain is yet to be proven [8]. There are currently two randomised clinical trials (RCT) listed that are investigating the use of STS in calciphylaxis (ISRCTN73380053 and NCT03150420) [28]. To date, no single approach has been shown to be significantly beneficial in altering outcome and 
Table 5 Association of calciphylaxis with all-cause mortality (Coxregression analysis-univariable model)

\begin{tabular}{llc}
\hline Variable & HR $(95 \%$ CI $)$ & p-value \\
\hline Calciphylaxis & $6.96(4.1-11.7)$ & $<\mathbf{0 . 0 0 1}$ \\
Age & $1.03(1.01-1.05)$ & $\mathbf{0 . 0 0 2}$ \\
Male & $1.16(0.73-1.83)$ & 0.54 \\
Caucasian & $3.7(1.4-10.4)$ & $\mathbf{0 . 0 1}$ \\
Diabetes mellitus & $1.79(1.1-2.9)$ & $\mathbf{0 . 0 1 3}$ \\
BMI & $1.01(0.97-1.04)$ & 0.86 \\
IHD & $1.61(0.96-2.68)$ & 0.06 \\
MI & $2.76(1.54-4.98)$ & 0.001 \\
PVD & $1.88(0.99-3.57)$ & 0.054 \\
CVA & $0.96(0.39-2.38)$ & 0.93 \\
Dialysis vintage & $0.99(0.99-1.01)$ & 0.36 \\
Haemoglobin & $0.96(0.94-0.97)$ & $<\mathbf{0 . 0 0 1}$ \\
Albumin & $0.89(0.87-92)$ & $<\mathbf{0 . 0 0 1}$ \\
C-reactive protein & $1.02(1.01-1.02)$ & $<\mathbf{0 . 0 0 1}$ \\
Corrected calcium & $1.55(0.41-5.77)$ & 0.51 \\
Phosphate & $0.97(0.63-1.46)$ & 0.83 \\
Parathyroid hormone & $1.00(1.00-1.01)$ & $\mathbf{0 . 0 0 1}$ \\
ESA & $1.66(1.03-2.67)$ & $\mathbf{0 . 0 4}$ \\
Vitamin D analogue & $1.24(0.78-1.97)$ & 0.36 \\
Phosphate binder & $0.78(0.44-1.39)$ & 0.40 \\
Calcimimetic & $1.09(0.57-2.08)$ & 0.78 \\
Vitamin K antagonist (warfarin) & $2.67(1.55-4.6)$ & $<\mathbf{0 . 0 0 1}$ \\
\hline
\end{tabular}

Hazard ratio for Parathyroid hormone included only 122 patients with available parathyroid hormone levels

$B M I$ Body mass index, $I H D$ ischemic heart disease, $M I$ myocardial infarction, $P V D$ peripheral vascular disease, CVA cerebrovascular accident, $E S A$ erythropoietin stimulating agent, $H R$ hazard ratio, $C I$ confidence interval the approach in management in the UKCS has been multifaceted similar to that observed in other cohorts [29]. Due to the rarity and detrimental nature of CUA, obtaining RCT evidence on the management of this condition has been a challenge and identification of the optimal treatment strategy remains elusive but interest from commercial and academic groups has increased recently. SNF472 is an intravenous formulation of myoinositol hexaphosphate that can inhibit the formation and growth of hydroxyapatite crystals. It has been shown to attenuate vascular calcification in haemodialysis patients (CaLIPSO study) [30]. A small Phase 2 open-label study investigation suggested a potential benefit of SNF472 in calciphylaxis and a Phase 3 multi-centre study is currently in progress (NCT04195906) [31, 32]. Until evidence is available from RCT, the management strategy for CUA should essentially be a multifaceted approach which includes medical modification of risk factors, wound care, pain management, surgery and advanced care planning [33].

Both univariable and multivariable cox-regression analysis have shown calciphylaxis as a strong and independent risk factor associated with all-cause mortality. The hazard ratio for the presence of calciphylaxis observed in our univariable model is similar to that observed by Mazhar et al. in 2001 (HR:7.29; CI 2.88-18.5; p < 0.001), although the impact of cardiovascular disease events was not demonstrated in their models [34]. We found that vitamin K antagonist use, high c-reactive protein, low albumin and low haemoglobin in association with CUA were markers of poor prognosis similar to observations from the French cohort [24]. The role of iron overload on the pathogenesis of CUA is debatable. Farah et al. have shown an association between iron exposure and iron deposition in the skin biopsies of patients with calciphylaxis. The authors hypothesise that iron deposition may not be causative but may create a favourable milieu. In contrast to this observational data, the
Table 6 Association of calciphylaxis with all-cause mortality (Cox-regression analysis-multivariable models $1,2,3)$

\begin{tabular}{|c|c|c|c|c|c|c|}
\hline \multirow[b]{2}{*}{ Variable } & \multicolumn{2}{|l|}{ Model-1 } & \multicolumn{2}{|l|}{ Model-2 } & \multicolumn{2}{|l|}{ Model-3 } \\
\hline & HR (95\% CI) & p-value & HR (95\% CI) & p-value & HR $(95 \%$ CI) & $\mathrm{p}$-value \\
\hline Calciphylaxis & $6.8(3.9-11.8)$ & $<0.001$ & $7.04(3.9-12.7)$ & $<0.001$ & $3.78(2.02-7.11)$ & $<0.001$ \\
\hline Age & $1.03(1.01-1.05)$ & 0.003 & $1.03(1.01-1.05)$ & 0.002 & $1.03(1.01-1.05)$ & 0.001 \\
\hline Ethnicity & $3.2(1.16-9.1)$ & 0.025 & $2.9(1.06-8.2)$ & 0.038 & $2.5(0.89-7.1)$ & 0.082 \\
\hline Diabetes mellitus & $1.72(1.08-2.74)$ & 0.02 & $1.75(1.09-2.8)$ & 0.02 & $1.69(1.05-2.73)$ & 0.029 \\
\hline Myocardial infarction & $1.78(0.97-3.2)$ & 0.06 & & & & \\
\hline Warfarin use & & & $1.11(0.60-2.05)$ & 0.73 & & \\
\hline Haemoglobin & & & & & $0.97(0.96-0.99)$ & 0.015 \\
\hline Albumin & & & & & $0.93(0.90-0.96)$ & $<0.001$ \\
\hline
\end{tabular}

Multivariate Model-1: Adjusted for calciphylaxis, age, ethnicity, diabetes mellitus and myocardial infarction

Multivariate Model-2: Adjusted for calciphylaxis, age, ethnicity, diabetes mellitus and warfarin use

Multivariate Model-3: Adjusted for calciphylaxis, age, ethnicity, diabetes mellitus, haemoglobin and albu$\min$ 


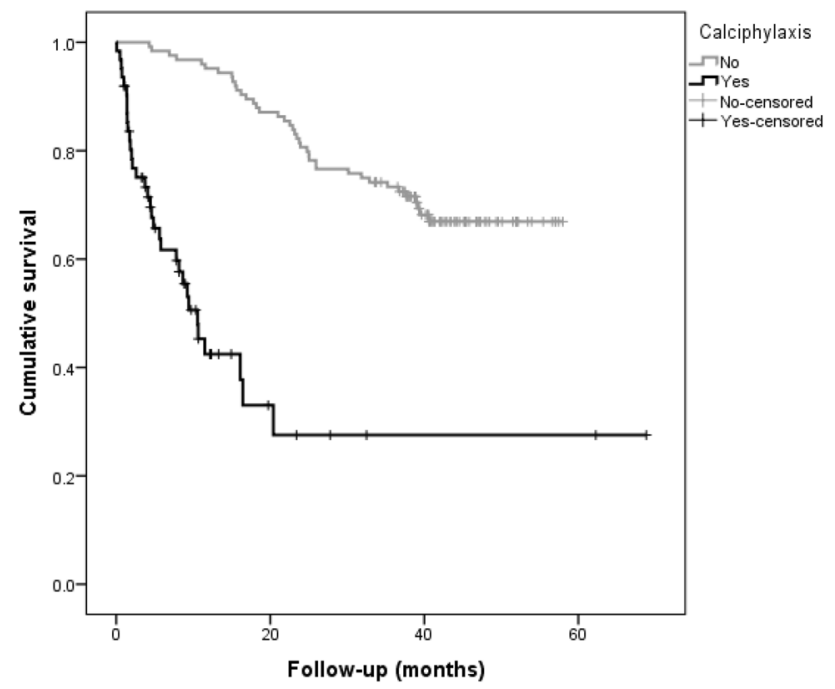

Fig. 2 Kaplan-Meier survival curve for presence of calciphylaxis in the matched dialysis populations

prospective, phase 3 randomised controlled trial of intravenous high dose iron versus low dose iron (PIVOTAL) in haemodialysis patients did not support this hypothesis, with no increased skin or subcutaneous-tissue disorders noted in the pro-active arm of the study $[35,36]$.

Our study is limited by the observational nature of the study methodology. The absence of cause of death data has limited our ability to identify the exact influence of calciphylaxis as a cause for mortality in the cohort. However, the study is strengthened by the well-structured registry-based data and a propensity matched comparative analysis with robust data from a dialysis cohort. Also, our study is novel in demonstrating the cardiovascular events history in the regression models showing association between calciphylaxis and all-cause mortality.

In conclusion, the UKCS endorses the findings from other registries that calciphylaxis has a very high mortality rate. This study has shown that calciphylaxis is a strong and independent risk factor associated with all-cause mortality. In addition, this study highlights that calciphylaxis lesions are slow to heal, if at all, and that no specific treatments have been associated with an improvement in outcomes. We await the outcome of future clinical trials to provide evidencebased treatment strategies. Until then a multifaceted, patient centred approach is appropriate for the management of this devastating and challenging condition.

Electronic supplementary material The online version of this article (https://doi.org/10.1007/s40620-020-00908-9) contains supplementary material, which is available to authorized users.

Acknowledgements The authors would like to thank participating renal centres and patients for contributing to this UKCS and CRISISHD study.
Authors' contributions Conception or design, or analysis and interpretation of data, or both-RC, AH, SS, PK. Drafting the article or revising it -RC, SS, PK. Providing intellectual content of critical importance to the work described-SS, JH, PK. Final approval of the version to be published -RC, AH, JH, PK, SS.

Funding The UK Calciphylaxis study was funded by an investigatorinitiated grant from Amgen.

Availability of data and material The datasets used and/or analysed during the current study are available from the corresponding author on reasonable request.

\section{Compliance with Ethical Standards}

Conflict of interest SS has received speaker fees and consultancy fees from Vifor Pharma and Napp pharmaceuticals and consultancy fees from Sanifit pharmaceuticals. SS is also the principle investigator for the UK Calciphylaxis study. No disclosures from the other authors.

Ethical approval and Informed Consent The CRISIS-HD adhered to the Declaration of Helsinki and has ethical approval for all observational data (REC 05/Q1404/188). The UK Calciphylaxis study gained ethical approval from the National Research Ethics Service (reference: 11/ NW/0528).

Open Access This article is licensed under a Creative Commons Attribution 4.0 International License, which permits use, sharing, adaptation, distribution and reproduction in any medium or format, as long as you give appropriate credit to the original author(s) and the source, provide a link to the Creative Commons licence, and indicate if changes were made. The images or other third party material in this article are included in the article's Creative Commons licence, unless indicated otherwise in a credit line to the material. If material is not included in the article's Creative Commons licence and your intended use is not permitted by statutory regulation or exceeds the permitted use, you will need to obtain permission directly from the copyright holder. To view a copy of this licence, visit http://creativecommons.org/licenses/by/4.0/.

\section{References}

1. Angelis M, Wong LL, Myers SA, Wong LM (1997) Calciphylaxis in patients on hemodialysis: a prevalence study. Surgery 122(1):1083-1090

2. Brandenburg VM, Kramann R, Rothe H, Kaesler N, Korbiel J, Specht P et al (2017) Calcific uraemic arteriolopathy (calciphylaxis): data from a large nationwide registry. Nephrol Dial Transplant 32(1):126-132

3. Weenig RH, Sewell LD, Davis MDP, McCarthy JT, Pittelkow MR (2007) Calciphylaxis: natural history, risk factor analysis, and outcome. J Am Acad Dermatol 56(4):569-579

4. Santos PW, He J, Tuffaha A, Wetmore JB (2017) Clinical characteristics and risk factors associated with mortality in calcific uremic arteriolopathy. Int Urol Nephrol 49(12):2247-2256

5. Mohammed IA, Sekar V, Bubtana AJ, Mitra S, Hutchison AJ (2008) Proximal calciphylaxis treated with calcimimetic "cinacalcet." Nephrol Dial Transpl 23:387-389

6. José V, Torregrosa CE, Durán X, Barros M, Blasco M, Arias (2012) Aleix Cases JMC. Successful treatment of calcific uraemic arteriolopathy with bisphosphonates. Nefrologia 32(3):329-334 
7. Truong DH, Riedhammer MM, Zinszer K (2019) Non-uraemic calciphylaxis successfully treated with pamidronate infusion. Int Wound J 16:250-5

8. Peng T, Zhuo L, Wang Y, Jun M, Li G, Wang L et al (2018 Jul) Systematic review of sodium thiosulfate in treating calciphylaxis in chronic kidney disease patients. Nephrology 23(7):669-675

9. Christiadi D, Singer RF (2017) Calciphylaxis in a dialysis patient successfully treated with high-dose vitamin K supplementation. Clin Kidney J 11(4):528-9

10. Ruderman I, Toussaint ND, Hawley CM, Krishnasamy R, Pedagogos E, Lioufas N et al (2019) The Australian Calciphylaxis Registry: reporting clinical features and outcomes of patients with calciphylaxis. Nephrol Dial Transplant. 2:1-8

11. Chiu DY, Green D, Abidin N, Hughes J, Odudu A, Sinha S et al (2017) Non-recruitment to and selection bias in studies using echocardiography in haemodialysis patients. Nephrology 22(11):864-71

12. Chiu DYY, Abidin N, Hughes J, Sinha S, Kalra PA, Green D (2016) Speckle tracking determination of mitral tissue annular displacement: comparison with strain and ejection fraction, and association with outcomes in haemodialysis patients. Int J Cardiovasc Imaging 32(10):1511-8

13. R Development Core Team (2018) R: A Language and Environment for Statistical Computing. Vienna, Austria: the R Foundation for Statistical Computing. ISBN: 3-900051-07-0. Available online at http://www.R-project.org/

14. Randolph JJ, Falbe K, Manuel AK, Balloun JL (2014) A step-bystep guide to propensity score matching in R. Pract Assessment. Res Eval 19(18):1-6

15. Vittinghoff E, McCulloch CE (2007) Relaxing the rule of ten events per variable in logistic and cox regression. Am J Epidemiol 165(6):710-718

16. Nigwekar SU, Kroshinsky D, Nazarian RM, Goverman J, Malhotra R, Jackson VA et al (2015) Calciphylaxis: risk factors, diagnosis, and treatment. Am J Kidney Dis 66(1):133-146

17. Nigwekar SU, Zhao S, Wenger J, Hymes JL, Maddux FW, Thadhani RI et al (2016) A nationally representative study of calcific uremic arteriolopathy risk factors. J Am Soc Nephrol 27(11):3421-3429

18. Hayden MR, Kolb LG, Khanna R (2006) Calciphylaxis and the cardiometabolic syndrome. J Cardiometab Syndr. 1(1):76-9

19. David T, Janigan DJ. Hirsch GAK (2000) and ASM. Calcified subcutaneous arterioles with infarcts of the subcutis and skin ('calciphylaxis') in chronic renal failure. Am J Kidney Dis 35(4):588-597

20. Rotondi S, De Martini N, Tartaglione L, Muci ML, Petrozza V, Porta $\mathrm{N}$ et al (2020) On the role of skin biopsy in the diagnosis of calcific uremic arteriolopathy: a case-based discussion. J Nephrol. 33(4):859-65

21. Dai L, Qureshi AR, Witasp A, Lindholm B, Stenvinkel P. Early Vascular Ageing and Cellular Senescence in Chronic Kidney Disease. Vol. 17, Computational and Structural Biotechnology Journal. Elsevier B.V.; 2019. p. 721-9
22. Sanchis P, Ho CY, Liu Y, Beltran LE, Ahmad S, Jacob AP et al (2019 Apr) Arterial "inflammaging" drives vascular calcification in children on dialysis. Kidney Int 95(4)(1):958-972

23. López-Mejías R, González-Gay MA (2019) IL-6: linking chronic inflammation and vascular calcification. Nat Rev Rheumatol. 15(8):457-9

24. Gaisne R, Péré M, Menoyo V, Hourmant M, Larmet-Burgeot D (2020) Calciphylaxis epidemiology, risk factors, treatment and survival among French chronic kidney disease patients: A casecontrol study. BMC Nephrol. 21:1

25. Danziger J (2008) Vitamin K-dependent proteins, warfarin, and vascular calcification. Clin J Am Soc Nephrol 3(5):1504-1510

26. Deen J, Schaider H (2019) The use of cinacalcet for the treatment of calciphylaxis in patients with chronic kidney disease: A comprehensive review. Australas J Dermatol. 60(3):e186-94

27. Floege J, Kubo Y, Floege A, Chertow GM, Parfrey PS (2015) The effect of cinacalcet on calcific uremic arteriolopathy events in patients receiving hemodialysis: The EVOLVE trial. Clin J Am Soc Nephrol. 10(5):800-7

28. Nigwekar SU, Thadhani R, Brandenburg VM. Calciphylaxis. Ingelfinger JR, editors. Vol. 378, New England Journal of Medicine. Massachussetts Medical Society; 2018. p. 1704-14

29. Harris C, Kiaii M, Lau W, Farah M (2018) Multi-intervention management of calcific uremic arteriolopathy in 24 patients. Clin Kidney J 11(5):704-709

30. Raggi P, Bellasi A, Bushinsky D, Bover J, Rodriguez M, Ketteler $M$ et al (2020) Slowing progression of cardiovascular calcification with snf472 in patients on hemodialysis: Results of a randomized phase 2b study. Circulation 141(9):728-739

31. Perelló J, Joubert PH, Ferrer MD, Canals AZ, Sinha S, Salcedo C (2018) First-time-in-human randomized clinical trial in healthy volunteers and haemodialysis patients with SNF472, a novel inhibitor of vascular calcification. Br J Clin Pharmacol. 84(12):2867-76

32. Brandenburg VM, Sinha S, Torregrosa JV, Garg R, Miller S, Canals AZ et al (2019) Improvement in wound healing, pain, and quality of life after 12 weeks of SNF472 treatment: a phase 2 open-label study of patients with calciphylaxis. J Nephrol. 32(5):811-21

33. Seethapathy H, Brandenburg VM, Sinha S, El-Azhary RA, Nigwekar SU (2019) Review: update on the management of calciphylaxis. QJM 112(1):29-34

34. Mazhar AR, Johnson RJ, Gillen D, Stivelman JC, Ryan MJ, Davis CL et al (2001) Risk factors and mortality associated with calciphylaxis in end-stage renal disease. Kidney Int 60(1):324-332

35. Farah M, Crawford RI, Levin A, Chan Yan C (2011) Calciphylaxis in the current era: emerging "ironic" features? Nephrol Dial Transplant. 26(1):191-5

36. Macdougall IC, White C, Anker SD, Bhandari S, Farrington K, Kalra PA et al (2019) Intravenous iron in patients undergoing maintenance hemodialysis. N Engl J Med 31(5):447-458 